\title{
Flavonoids from the flower of Chrysanthemum morifolium
}

\author{
Hyoung-Geun Kim ${ }^{1} \cdot$ Jung-Hwan Ko ${ }^{1}$ Yeong-Geun Lee ${ }^{1}$ Ha-Seung Pak ${ }^{2}$. \\ Dong-Chan Kim ${ }^{2}$ - Kuk-Seong Son ${ }^{2}$ - Yun-Su Baek ${ }^{3}$ - Oh-Keun Kwon ${ }^{3}$. \\ Hak-Ki Shin ${ }^{3} \cdot$ Nam-In Baek ${ }^{1}$ (D)
}

\section{국화(Chrysanthemum morifolium)꽃으로부터 Flavonoid의 분리 및 동정}

\author{
김형근 ${ }^{1}$ · 고정환 ${ }^{1}$ - 이영 근 ${ }^{1}$ - 박하숭 ${ }^{2}$. 김동찬 ${ }^{2}$ - 손국성 ${ }^{2}$ 백윤수 ${ }^{3}$. \\ 권오근 $^{3} \cdot$ 신학기 $^{3} \cdot$ 백남인 $^{1}$
}

Received: 5 September 2016 / Accepted: 7 September 2016 / Published Online: 31 December 2016

(C) The Korean Society for Applied Biological Chemistry 2016

\begin{abstract}
Chrysanthemum morifolium flowers were extracted with $80 \%$ aqueous $\mathrm{MeOH}$, and the concentrated extract was partitioned into EtOAc, n-butyl alcohol $(n-\mathrm{BuOH})$, and water fractions. The repeated silica gel and octadecyl silica gel column chromatographies for the EtOAc and $n$ - $\mathrm{BuOH}$ fractions led to isolation of four flavonoids. The chemical structures of the compounds were determined as acacetin (1), apigenin (2), apigenin7-O- $\beta$-D-glucopyanoside (3), acacetin-7- $O$ - $\beta$-D-glucopyranoside (4) based on spectroscopic data analyses including nuclear magnetic resonance, mass spectrometry, and infrared spectrometry.
\end{abstract}

Keywords Acacetin - Acacetin-7-O- $\beta$-D-glucopyranoside $\cdot$ Apigenin - Apigenin-7-O- $\beta$-D-glucopyanoside $\cdot$ Chrysanthemum morifolium - Flavonoid · Flower

Nam-In Baek $(\bowtie)$

E-mail:nibaek@khu.ac.kr

${ }^{1}$ Graduate School of Biotechnology and Department of Oriental Medicine Biotechnology, Kyung Hee University, Yongin 17104, Republic of Korea

${ }^{2}$ Flower Research Institute, Chungcheongnam-do ARES, Yesan 32425, Republic of Korea

${ }^{3}$ Floriculture Research Division, National Institute of Horticultural and Herbal Science, RDA, Wanju 55365, Republic of Korea

This is an Open Access article distributed under the terms of the Creative Commons Attribution Non-Commercial License (http://creativecommons. org/licenses/by-nc/3.0/) which permits unrestricted non-commercial use, distribution, and reproduction in any medium, provided the original work is properly cited.

\section{서 론}

국화는 국화과(Compositae), 국화속(Chrysanthemum)에 속하는 다년생 초본식물로, 아시아에 주로 서식하며, 길가나 산, 들판 에서 자란다. 주요한 용도는 관상용이나, 동아시아 문화권에서 는 차나 방향제 등으로도 사용된다. 식물학적 특징으로는 0.3 0.9 m까지 자라며, 꽃은 가을에 개화하고, 청색, 녹색, 오렌 지색, 흰색 등 여러가지 색이 있다. 국화는 스탠다드형 국화, 스 프레이형 국화, 화분국화 등으로 분류할 수 있는데, 현재 국내 에서만도 700 종 이상의 품종이 육종개발되어있다. 스탠다드형이 전체의 $80 \%$ 이상으로 생산량이 가장 많다(Ministry of Agriculture, Food and Rural Affairs 2014). 국화꽃의 밝혀진 활성으로서는 항산화(Yuan 등, 2015), 혈관형성 저해(Zheng 등, 2015), 항 HIV바이러스(Lee 등, 2003), 항돌연변이(Miyazawa 와 Hisama 2003), 세포독성(Xie 등, 2009), 간독성 저해, 유전자독성 저해 (Lee 등, 2011)활성 등이 보고되어 있다. 국화의 이러한 다양한 활성에 주목하며 국화품종 중 가장 생산량이 많은 스탠다드형 국화품종인 '백선'을 가지고 생리활성물질을 분리하고, 성분 분 석을 통해 활용방안을 모색하고자 본 연구를 시작하였다.

\section{재료 및 방법}

\section{실험 재료}

본 실험에서 사용한 국화 '백선'(C. morifolium)은 스탠다드형 국화로 2015년 9월에 양재꽃시장(서울, 대한민국)에서 흰색 꽃 을 구입하였으며, 충청남도농업기술원 화훼연구소(충청남도 예 산군 오가면 역탑리) 박하승 박사가 동정하였다. 표본시료(KHUNPCL-20150930)는 경희대학교 천연물화학실에 보관되어 있다. 
시약 및 기기

시약 및 기기는 이전 실험과 동일하게 사용하였다(Lee 등, 2016).

\section{추출 및 분리}

국화 '백선'의 건조한 꽃 $485.0 \mathrm{~g}$ 을 $80 \% \mathrm{MeOH}$ 수용액 $(50 \mathrm{~L})$ 으로 24 시간씩 3 번 실온에서 추출하였다. 얻어진 여액을 감압 농축하여 $\mathrm{MeOH}$ 추출물 $(246.4 \mathrm{~g})$ 을 얻었다. 얻어진 $\mathrm{MeOH}$ 추 출물은 물 $(1 \mathrm{~L})$ 과 ethyl acetate $(\mathrm{EtOAc}, 1 \mathrm{~L} \times 3)$ 로 분배 추출하 였고, 다시 물층을 $n$-butyl alcohol $(n-\mathrm{BuOH}, 800 \mathrm{~mL} \times 3)$ 로 분 배 추출하였다. 각층을 감압농축하여 $\mathrm{EtOAc}$ 분획 $(\mathrm{CBE}, 8.5 \mathrm{~g})$, $n-\mathrm{BuOH}$ 분획 $(\mathrm{CBB}, 27.7 \mathrm{~g})$ 및 물 분획 $(\mathrm{CBW}, 188 \mathrm{~g})$ 을 얻었다. EtOAc 분획 $(\mathrm{CBE}, 8.5 \mathrm{~g})$ 에 대하여 silica gel $\left(\mathrm{SiO}_{2}\right)$ column chromatography (c.c., $\phi 4.4 \times 15.0 \mathrm{~cm}, \mathrm{CHCl}_{3}-\mathrm{MeOH}=10: 1 \rightarrow 5: 1$, 각 $2.0 \mathrm{~L}$ )를 실시하여 11 개의 분획 $(\mathrm{CBE}-1 \sim \mathrm{CBE}-11)$ 을 얻었다. 그 중에서 $\mathrm{CBE}-2$ 분획 $[423.6 \mathrm{mg}$, elution volume/total volume $(\mathrm{Ve} / \mathrm{Vt}) 0.032-086]$ 에 대하여 $\mathrm{SiO}_{2}$ c.c. $\left(\phi 3.0 \times 16.0 \mathrm{~cm}, \mathrm{CHCl}_{3}-\right.$ $\mathrm{MeOH}$-water $=50: 3: 1 \rightarrow 24: 3: 1$, 각 $470 \mathrm{~mL}$ )를 실시하여 화합물 2 (CBE-2-6, $6.9 \mathrm{mg}, \mathrm{Ve} / \mathrm{Vt}$ 0.207, $\mathrm{SiO}_{2}$ TLC $\mathrm{R}_{\mathrm{f}}$ 0.61, $\mathrm{CHCl}_{3}$ $\mathrm{MeOH}-$ water=50:3:1)를 분리하였다. CBE-9 분획 $(284.5 \mathrm{mg}, \mathrm{Ve} /$ Vt $0.535-649)$ 을 $\mathrm{SiO}_{2}$ c.c. $\left(\phi 3.0 \times 15.0 \mathrm{~cm}, \mathrm{CHCl}_{3}-\mathrm{MeOH}\right.$-water $=30: 3: 1 \rightarrow 27: 3: 1$, 각 $3.5 \mathrm{~L})$ 를 실시하여 총 13 개의 분획 $(\mathrm{CBE}-9-$ 1 CBE-9-13)을 얻었다. 그 중 CBE-9-9 분획 $(61.9 \mathrm{mg}, \mathrm{Ve} / \mathrm{Vt}$ $0.533-632)$ 에 대하여 octadecyl silica gel (ODS) c.c. $(\phi 2.0 \times 5.0$ $\mathrm{cm}, \mathrm{MeOH}-w a t e r=1: 2,1.3 \mathrm{~L}$ ) 를 실시하여 화합물 3 (CBE-99-5, $7.4 \mathrm{mg}, \quad \mathrm{Ve} / \mathrm{Vt} \quad 0.322-410, \quad \mathrm{SiO}_{2} \quad \mathrm{TLC} \quad \mathrm{R}_{\mathrm{f}} 0.49 \quad \mathrm{CHCl}_{3}-$ $\mathrm{MeOH}$-water=9:3:1)을 분리하였다. $n-\mathrm{BuOH}$ 분획(CBB, 27.7 $\mathrm{g})$ 에 대하여 $\mathrm{SiO}_{2}$ c.c. $\left(\phi 7.0 \times 10.0 \mathrm{~cm}, \mathrm{CHCl}_{3}-\mathrm{MeOH}=7: 1 \rightarrow 5: 1\right.$ $\rightarrow 3: 1 \quad \mathrm{CHCl}_{3}-\mathrm{MeOH}-$ water=12:3:1 $\rightarrow 10: 3: 1 \rightarrow 7: 3: 1 \rightarrow 65: 35: 10$, 각 $1 \mathrm{~L})$ 를 실시하여 13 개의 분획 $(\mathrm{CBB}-1 \sim \mathrm{CBB}-13)$ 을 얻었다. 그 중 에서 $\mathrm{CBB}-7$ 분획 $(797.6 \mathrm{mg}, \mathrm{Ve} / \mathrm{Vt} \quad 0.255-318)$ 에 대하여 $\mathrm{SiO}_{2}$ c.c. $\left(\phi 4.5 \times 15.0 \mathrm{~cm}, \mathrm{CHCl}_{3}-\mathrm{MeOH}=4: 1,2.1 \mathrm{~L}\right)$ 를 실시하여 화합 물 4 (CBB-7-4, $28.3 \mathrm{mg}, \mathrm{Ve} / \mathrm{Vt}$ 0.192-205, $\mathrm{SiO}_{2}$ TLC $\mathrm{R}_{\mathrm{f}}$ $\left.0.27 \mathrm{CHCl}_{3}-\mathrm{MeOH}=3: 1\right)$ 를 분리하였다. $\mathrm{CBB}-10$ 분획 $(1.02 \mathrm{~g}$, $\mathrm{Ve} / \mathrm{Vt}$ 0.563-899)에 대하여 $\mathrm{SiO}_{2}$ c.c. $\left(\phi 4.0 \times 16.0 \mathrm{~cm}, \mathrm{CHCl}_{3-}\right.$ $\mathrm{MeOH}$-water=10:3:1 $\rightarrow 8: 3: 1 \rightarrow 7: 3: 1$, 각 $2 \mathrm{~L}$ )를 실시하여 총 9개 의 분획(CBB-10-1 CBB-10-9)을 얻었으며, 화합물 3 (CBB-10$5,253.9 \mathrm{mg}, \mathrm{Ve} / \mathrm{Vt} \quad 0.182-482, \quad \mathrm{SiO}_{2} \quad \mathrm{TLC} \quad \mathrm{R}_{\mathrm{f}} 0.60 \quad \mathrm{CHCl}_{3}-$ $\mathrm{MeOH}-w a t e r=65: 35: 10)$ 을 분리하였다. CBB-10-4 분획 $(19.5 \mathrm{mg}$, $\mathrm{Ve} / \mathrm{Vt} \quad 0.150-179)$ 에 대하여 $\mathrm{SiO}_{2}$ c.c. $\left(\phi 1.5 \times 16.0 \mathrm{~cm}, \mathrm{CHCl}_{3}-\right.$ $\mathrm{MeOH}-w a t e r=50: 3: 1,1.6 \mathrm{~L}$ )를 실시하여 화합물 1 (CBB-10-4-1, $13.0 \mathrm{mg}, \mathrm{Ve} / \mathrm{Vt}$ 0.007-296, $\mathrm{SiO}_{2}$ TLC $\mathrm{R}_{\mathrm{f}} 0.42 \mathrm{CHCl}_{3}-\mathrm{MeOH}-$ water=18:3:1)을 분리하였다. CBB-10-6 분획 $(405.2 \mathrm{mg}, \mathrm{Ve} / \mathrm{Vt}$ $0.146-216)$ 에 대하여 $\mathrm{SiO}_{2}$ c.c. $\left(\phi 2.5 \times 16.0 \mathrm{~cm}, \mathrm{CHCl}_{3}-\mathrm{MeOH}-\right.$ water= $18: 3: 1 \rightarrow 12: 3: 1$, 각 $2.5 \mathrm{~L}$ )를 실시하여 화합물 4 (CBB$10-6-4,13.8 \mathrm{mg}, \mathrm{Ve} / \mathrm{Vt}$ 0.139-372, $\mathrm{SiO}_{2}$ TLC $\mathrm{R}_{\mathrm{f}} 0.52 \mathrm{CHCl}_{3}$ $\mathrm{MeOH}-$ water=9:3:1)를 분리하였다.

화합물 1 (apigenin): 무정형 황색 분말(pyridine); negative FAB-mass spectrometry (MS) $m / z \quad 269 \quad[\mathrm{M}-\mathrm{H}]^{-}$; infrared spectrometry (IR) (KBr, v) 3427, $1629,1580 \mathrm{~cm}^{-1}$; ${ }^{1} \mathrm{H}$ nuclear magnetic resonance (NMR) (400 MHz, pyridine- $\left.d_{5}, \delta_{\mathrm{H}}\right) 7.85$ $(2 \mathrm{H}, \mathrm{d}, J=8.0 \mathrm{~Hz}, \mathrm{H}-2,6), 7.17(2 \mathrm{H}, \mathrm{d}, J=8.0 \mathrm{~Hz}, \mathrm{H}-3,5)$,
$6.82(1 \mathrm{H}, \mathrm{s}, \mathrm{H}-3), 6.80(1 \mathrm{H}, \mathrm{s}, \mathrm{H}-8), 6.70$ (1H, s, H-6). ${ }^{13} \mathrm{C}$ NMR $\left(100 \mathrm{MHz}\right.$, pyridine- $\left.d_{5}, \delta_{\mathrm{C}}\right) 182.5(\mathrm{C}-4), 166.4$ (C7), 164.3 (C-2), 162.9 (C-5), 162.5 (C-4), 158.3 (C-9), 128.7 (C-2, 6), 122.0 (C-1), 116.7 (C-10), 104.8 (C-3, 5), 103.6 (C-3), 98.7 (C-6), 94.7 (C-8).

화합물 2 (acacetin): 무정형 황색 분말(pyridine): positive FAB-MS m/z $307[\mathrm{M}+\mathrm{Na}]^{+}$; IR (KBr, v) 3259, 1653, 1590 $\mathrm{cm}^{-1}$; ${ }^{1} \mathrm{H}$ NMR $\left(400 \mathrm{MHz}\right.$, pyridine- $\left.d_{5}, \delta_{\mathrm{H}}\right) 7.85(2 \mathrm{H}, \mathrm{d}$, $J=8.0 \mathrm{~Hz}, \mathrm{H}-2,6), 7.17$ (2H, d, $J=8.0 \mathrm{~Hz}, \mathrm{H}-3,5), 6.82$ $(1 \mathrm{H}, \mathrm{s}, \mathrm{H}-3), 6.80(1 \mathrm{H}, \mathrm{s}, \mathrm{H}-8), 6.70(1 \mathrm{H}, \mathrm{s}, \mathrm{H}-6), 3.59$ $\left(3 \mathrm{H}, \quad \mathrm{s}, \quad \mathrm{OCH}_{3}-7\right) .{ }^{13} \mathrm{C}$ NMR $\left(100 \mathrm{MHz}\right.$, pyridine- $\left.d_{5}, \delta_{\mathrm{C}}\right)$ 182.5 (C-4), 166.4 (C-7), 164.3 (C-2), 162.9 (C-5), 162.5 (C-4), 158.3 (C-9), 128.7 (C-2, 6), 122.0 (C-1), 116.7 (C10), 104.8 (C-3, 5), 103.6 (C-3), 98.7 (C-6), 94.7 (C-8), $55.6\left(\mathrm{OCH}_{3}-7\right)$

화합물 3 (apigenin-7-O- $\beta$-D-glucopyranoside, cosmetin): 무정형 황색 분말(pyridine); negative FAB-MS $m / z 431$ [M-H] $]^{-}$; IR $(\mathrm{KBr}, v) 3345,1635,1605,1512,1485 \mathrm{~cm}^{-1} ;{ }^{1} \mathrm{H}$ NMR (400 MHz, pyridine- $\left.d_{5}, \delta_{\mathrm{H}}\right) 7.85(2 \mathrm{H}, \mathrm{d}, J=8.0 \mathrm{~Hz}, \mathrm{H}-2,6)$, $7.17(2 \mathrm{H}, \mathrm{d}, J=8.0 \mathrm{~Hz}, \mathrm{H}-3,5), 6.82(1 \mathrm{H}, \mathrm{s}, \mathrm{H}-3), 6.80$ $(1 \mathrm{H}, \mathrm{s}, \mathrm{H}-8), 6.70(1 \mathrm{H}, \mathrm{s}, \mathrm{H}-6), 5.82(1 \mathrm{H}, \mathrm{d}, J=7.2 \mathrm{~Hz}, \mathrm{H}-$ 1), $3.97(1 \mathrm{H}$, overlapped, H-3), $3.94(1 \mathrm{H}, \mathrm{dd}, J=12.0,1.6$ Hz, H-6a), 3.74 (1H, dd, J=12.0, $5.2 \mathrm{~Hz}, \mathrm{H}-6 \mathrm{~b}), 3.48(1 \mathrm{H}$, overlapped, H-5), 3.47 (1H, overlapped, H-4), $3.15(1 \mathrm{H}$, overlapped, $\mathrm{H}-2) . \quad{ }^{13} \mathrm{C}$ NMR $\left(100 \mathrm{MHz}\right.$, pyridine- $\left.d_{5}, \delta_{\mathrm{C}}\right)$ 182.5 (C-4), 166.4 (C-7), 164.3 (C-2), 162.9 (C-5), 162.5 (C-4), 158.3 (C-9), 128.7 (C-2, 6), 122.0 (C-1), 116.7 (C10), 104.8 (C-3, 5), 103.6 (C-3), 101.6 (C-1), 98.7 (C-6), 94.7 (C-8), 78.4 (C-3), 77.8 (C-5), 74.8 (C-2), 71.3 (C-4), $62.3(\mathrm{C}-6)$.

화합물 4 (acacetin-7-O- $\beta$-D-glucopyranoside, tilianin): 무정형 백색 분말(pyridine); positive FAB-MS $m / z 469[\mathrm{M}+\mathrm{Na}]^{+}$; IR $(\mathrm{KBr}, \quad v) 3394, \quad 3072, \quad 1656 \mathrm{~cm}^{-1} ;{ }^{1} \mathrm{H}$ NMR (400 MHz, pyridine- $\left.d_{5}, \delta_{\mathrm{H}}\right) 7.85(2 \mathrm{H}, \mathrm{d}, J=8.0 \mathrm{~Hz}, \mathrm{H}-2,6), 7.17(2 \mathrm{H}, \mathrm{d}$, $J=8.0 \mathrm{~Hz}, \mathrm{H}-3,5), 6.82$ (1H, s, H-3), 6.80 (1H, s, H-8), $6.70(1 \mathrm{H}, \mathrm{s}, \mathrm{H}-6), 5.82(1 \mathrm{H}, \mathrm{d}, J=7.2 \mathrm{~Hz}, \mathrm{H}-1), 3.97(1 \mathrm{H}$, overlapped, H-3), 3.94 (1H, dd, $J=12.0,1.6 \mathrm{~Hz}, \mathrm{H}-6 \mathrm{a}), 3.74$ (1H, dd, $J=12.0,5.2 \mathrm{~Hz}, \mathrm{H}-6 \mathrm{~b}), 3.59\left(3 \mathrm{H}, \mathrm{s}, \mathrm{OCH}_{3}-7\right), 3.48$ $(1 \mathrm{H}$, overlapped, $\mathrm{H}-5), 3.47(1 \mathrm{H}$, overlapped, H-4), 3.15 (1H, overlapped, H-2). ${ }^{13} \mathrm{C}$ NMR $\left(100 \mathrm{MHz}\right.$, pyridine- $\left.d_{5}, \delta_{\mathrm{C}}\right)$ 182.5 (C-4), 166.4 (C-7), 164.3 (C-2), 162.9 (C-5), 162.5 (C-4), 158.3 (C-9), 128.7 (C-2, 6), 122.0 (C-1), 116.7 (C10), 104.8 (C-3, 5), 103.6 (C-3), 101.6 (C-1), 98.7 (C-6), 94.7 (C-8), 78.4 (C-3), 77.8 (C-5), 74.8 (C-2), 71.3 (C-4), 62.3 (C-6), $55.6\left(\mathrm{OCH}_{3}-7\right)$

\section{결과 및 고찰}

화합물 1은 negative FAB-MS 에서 $m / z 269$ [M-H] 의 분자이 온 peak가 관측되어 분자량을 270 으로 결정하였다. IR 스펙트 럼으로부터 공역화된 카보닐기 $\left(1629 \mathrm{~cm}^{-1}\right)$, 수산기 $\left(3427 \mathrm{~cm}^{-1}\right)$ 와 
<smiles>[R20]Oc1cc(O)c2c(=O)cc(-c3ccc([R20])cc3)oc2c1</smiles>

\begin{tabular}{ccc} 
& $\mathrm{R}_{1}$ & $\mathrm{R}_{2}$ \\
\hline $\mathbf{1}$ & $-\mathrm{H}$ & $-\mathrm{H}$ \\
2 & $-\mathrm{CH}_{3}$ & $-\mathrm{H}$ \\
3 & $-\mathrm{H}$ & $-\mathrm{Glc}$ \\
4 & $-\mathrm{CH}_{3}$ & $-\mathrm{Glc}$
\end{tabular}

Fig. 1 Chemical structures of flavonoids 1-4 from the flower of Chrysanthemum morifolium. Glc: $\beta$-D-glucopyranosyl

이중결합 $\left(1580 \mathrm{~cm}^{-1}\right)$ 이 있는 것으로 확인되었다. ${ }^{1} \mathrm{H}$ NMR $(400$ $\mathrm{MHz}$, pyridine- $\left.d_{5}, \delta_{\mathrm{H}}\right)$ 스펙트럼에서 적분값이 2 인 2 개의 olefin methine proton signal $\left(\delta_{\mathrm{H}} 7.85,2 \mathrm{H}, \mathrm{d}, J=8.0 \mathrm{~Hz} ; 7.17,2 \mathrm{H}\right.$, $\mathrm{d}, J=8.0 \mathrm{~Hz}$ )로부터 para-이치환 벤젠 구조가 존재함을 확인하 였다. 또한 2개의 olefin methine proton signal $\left(\delta_{\mathrm{H}} 6.80,1 \mathrm{H}\right.$, $\mathrm{s} ; 6.70,1 \mathrm{H}, \mathrm{s})$ 으로부터 $1,2,3,5$-사치환 벤젠 구조가 존재함을 확인하였다. 또한 1 개의 olefin methine proton signal $\left(\delta_{\mathrm{H}} 6.82\right.$, $1 \mathrm{H}, \mathrm{s})$ 을 관측하였으며, 이를 통해 이 화합물이 flavone 화합물 임을 예상하였다. ${ }^{13} \mathrm{C} \mathrm{NMR}\left(100 \mathrm{MHz}\right.$, pyridine- $\left.d_{5}, \delta_{\mathrm{C}}\right)$ 스펙 트럼에서 탄소수가 15 개임을 확인하였으며, 이를 통해 flavone 화합물임을 확인하였다. 1개의 conjugated ketone carbon signal $\left(\delta_{\mathrm{C}} 182.54\right), 5$ 개의 oxygenated olefin quaternary carbon signal $\left(\delta_{\mathrm{C}} 166.4 ; 164.3 ; 162.9 ; 162.5 ; 158.3\right)$ 을 확인하였고, 2 개의 olefin quaternary carbon signal $\left(\delta_{\mathrm{C}} 122.0 ; 116.7\right)$ 을 확 인하였으며, 7개의 olefin methine carbon signal [ $\delta_{\mathrm{C}} 128.7$ $(\times 2)$; $104.8(\times 2)$; $103.6 ; 98.7 ; 94.7]$ 을 확인하였다. 위의 data 를 문헌값(Wang 등, 2015)과 비교하여 화합물 1을 5,7,4trihydroxyflavone, apigenin으로 구조 동정 하였다.

화합물 2는 positive FAB-MS에서 $m / z 307[\mathrm{M}+\mathrm{Na}]^{+}$의 분자 이온 peak가 관측되어 분자량을 284로 결정하였다. 화합물 1과 분자량이 $14 \mathrm{amu}$ 차이가 나는 것으로부터 methyl기가 한 개 더 존재함을 예상할 수 있었다. IR 스펙트럼으로부터 공역화된 카보닐기 $\left(1653 \mathrm{~cm}^{-1}\right)$, 수산기 $\left(3259 \mathrm{~cm}^{-1}\right)$ 와 이중결합 $\left(1590 \mathrm{~cm}^{-1}\right)$ 이 있는 것으로 확인되었다. ${ }^{1} \mathrm{H}$ NMR $\left(400 \mathrm{MHz}\right.$, pyridine- $d_{5}$, $\left.\ddot{\mathrm{a}}_{\mathrm{H}}\right)$ 과 ${ }^{13} \mathrm{C} \mathrm{NMR}\left(100 \mathrm{MHz}\right.$, pyridine- $\left.d_{5}, \delta_{\mathrm{C}}\right)$ spectrum을 통하 여 화합물 1과 같은 구조에 하나의 수산기 대신 methoxy $\left(\delta_{\mathrm{H}}\right.$ $3 \mathrm{H}, \mathrm{s} ; \delta_{\mathrm{C}}$ 55.6)기가 결합했음을 알 수 있었다. Methoxy기의 결합위치를 확인하기 위해 $\mathrm{gHMBC}$ 를 측정하였다. 그 결과 methoxyl의 proton signal $\left(\delta_{\mathrm{H}} 3.59\right)$ 이 C-4의 oxygenated olefin quaternary carbon signal $\left(\delta_{\mathrm{C}}\right.$ 162.5)과 cross peak를 보여 C-4 에 methoxy기가 결합해 있음을 확인하였다. 위의 data를 문헌 값(Malmir 등, 2015)과 비교하여 화합물 2를 5,7-dihydroxy-4methoxyflavone, acacetin으로 구조 동정 하였다.

화합물 3은 negative FAB-MS 에서 $m / z 431$ [M-H] $]^{-}$의 분
자이온 peak가 관측되어 분자량을 432로 결정하였다. 화합물 1 과 분자량이 $162 \mathrm{amu}$ 차이가 나는 것으로부터 육탄당이 한 개 더 존재함을 예상할 수 있었다. IR 스펙트럼으로부터 공역화된 카보닐기 $\left(1635 \mathrm{~cm}^{-1}\right)$, 수산기 $\left(3345 \mathrm{~cm}^{-1}\right)$, 방향족 고리(1605, $\left.1512,1485 \mathrm{~cm}^{-1}\right)$ 가 존재하는 것으로 확인되었다. ${ }^{1} \mathrm{H} \mathrm{NMR}$ (400 MHz, pyridine- $\left.d_{5}, \delta_{\mathrm{H}}\right)$ 과 ${ }^{13} \mathrm{C} \mathrm{NMR}(100 \mathrm{MHz}$, pyridine$\left.d_{5}, \delta_{\mathrm{C}}\right)$ spectrum을 통하여 화합물 1 과 매우 비슷한 구조에 당 이 하나 더 결합했음을 알 수 있었다. 당에서 유래한 1 개의 hemiacetal signal $\left(\delta_{\mathrm{C}} 101.6 ; \delta_{\mathrm{H}} 5.82,1 \mathrm{H}, \mathrm{d}, J=7.2 \mathrm{~Hz}\right), 4$ 개의 oxygenated methine signal $\left(\delta_{\mathrm{C}} 78.4 ; 77.8 ; 74.8 ; 71.3\right.$; $\left.\delta_{\mathrm{H}} 3.97 ; 3.48 ; 3.47 ; 3.15\right)$, 1 개의 oxygenated methylene signal $\left(\delta_{\mathrm{C}} 62.3 ; \delta_{\mathrm{H}} 3.94,1 \mathrm{H}, \mathrm{dd}, J=12.0,1.6 \mathrm{~Hz} ; \delta_{\mathrm{H}} 3.74\right.$, $1 \mathrm{H}, \mathrm{dd}, J=12.0,5.2 \mathrm{~Hz}$ )의 chemical shift 및 anomer proton signal의 결합정수 $(J=7.2 \mathrm{~Hz})$ 로부터 당의 구조가 $\beta$-glucopyranose 임을 확인하였다. 당의 결합위치를 확인하기 위하여 $\mathrm{gHMBC}$ 를 측정하였다. 그 결과 anomer proton signal $\left(\delta_{\mathrm{H}} 5.82, \mathrm{H}-1\right)$ 이 C-7의 oxygenated olefin quaternary carbon signal $\left(\delta_{\mathrm{C}} 166.4\right)$ 과 cross peak를 보여 glucose가 7번에 결합하고 있음을 알 수 있었다. 위의 data를 문헌값(Lee 등, 2013)과 비교하여 화합물 3 을 cosmetin으로 구조 동정 하였다.

화합물 4는 positive FAB-MS에서 $m / z 469[\mathrm{M}+\mathrm{Na}]^{+}$의 분자 이온 peak가 관측되어 분자량을 446으로 결정하였다. 화합물 2 와 분자량이 $162 \mathrm{amu}$ 차이가 나는 것으로부터 육탄당이 한 개 더 존재함을 예상할 수 있었다. IR 스펙트럼으로부터 공역화된 카보닐기 $\left(1656 \mathrm{~cm}^{-1}\right)$, 수산기 $\left(3394 \mathrm{~cm}^{-1}\right)$, 방항족 고리 $\left(3072 \mathrm{~cm}^{-1}\right)$ 가 존재하는 것으로 확인되었다. ${ }^{1} \mathrm{H}$ NMR $(400 \mathrm{MHz}$, pyridine $\left.d_{5}, \delta_{\mathrm{H}}\right)$ 과 ${ }^{13} \mathrm{C} \mathrm{NMR}\left(100 \mathrm{MHz}\right.$, pyridine $\left.d_{5}, \delta_{\mathrm{C}}\right)$ spectrum을 통하여 화합물 2 와 매우 비슷한 구조에 당이 하나 더 결합했음 을 알 수 있었다. 당에서 유래한 1 개의 hemiacetal signal $\left(\delta_{\mathrm{C}}\right.$ $\left.101.6 ; \delta_{\mathrm{H}} 5.82,1 \mathrm{H}, \mathrm{d}, J=7.2 \mathrm{~Hz}\right), 4$ 개의 oxygenated methine signal $\left(\delta_{\mathrm{C}} 78.4 ; 77.8 ; 74.8 ; 71.3 ; \delta_{\mathrm{H}} 3.97 ; 3.48 ; 3.47 ; 3.15\right)$, 1 개의 oxygenated methylene signal $\left(\delta_{\mathrm{C}} 62.3 ; \delta_{\mathrm{H}} 3.94,1 \mathrm{H}\right.$, $\left.\mathrm{dd}, J=12.0,1.6 \mathrm{~Hz} ; \delta_{\mathrm{H}} 3.74,1 \mathrm{H}, \mathrm{dd}, J=12.0,5.2 \mathrm{~Hz}\right)$ 의 chemical shift 및 anomer proton signal의 결합정수 $(J=7.2 \mathrm{~Hz})$ 로부터 당의 구조가 $\beta$-glucopyranose임을 확인하였다. 당의 결 합위치를 확인하기 위하여 $\mathrm{gHMBC}$ 를 측정하였다. 그 결과 anomer proton signal $\left(\delta_{\mathrm{H}} 5.82, \mathrm{H}-1\right)$ 이 C-7의 oxygenated olefin quaternary carbon signal $\left(\delta_{\mathrm{C}}\right.$ 166.4)과 cross peak를 보 여 glucose가 7번에 결합하고 있음을 알 수 있었다. 위의 data 를 문헌값(Xiang 등, 2013)과 비교하여 화합물 4를 tilianin으로 구조 동정 하였다.

Apigenin (1)은 항산화 활성(Agar 등, 2015), 항염 활성 (Tavares 등, 2014), 미백 활성(Karim 등, 2014), 주름개선 활성 (Yu 등, 2015), 간세포보호 활성(Wang 등, 2016), 항암 활성 (Coombs 등, 2016)등이 보고되어 있다. Acacetin (2)은 항산화 활성(Yadav와 Yadava 2013), 항균 활성(Komape 등, 2014), 미 백 활성, 주름개선 활성(Karim 등, 2014) 등이 보고되어 있다. Cosmetin (3)은 항산화 활성(Aprotosoaie 등, 2016), 항박테리아 활성(Karlickova 등, 2016), 미백 활성(Bouzaiene 등, 2016)등이 보고되어 있다. Tilianin (4)은 항산화 활성(Kang 등, 1999), 항 암 활성(Mohamed 2010), 항알레르기 활성(Xie 등, 2012), 항염 활성(Semwal 과 Semwal 2012), 미백 활성(Thanigaimalai 등, 
2010) 등이 보고되어 있다. 이와 같은 결과를 통해 위의 flavonoid 화합물들이 국화꽃 추출물의 주요한 활성 본체인 것 을 확인 하였다. 또한 공통적으로 미백 활성, 항산화 활성, 항 염 활성, 주름 개선 활성, 항균 활성, 항알레르기 활성 등의 기 능성 화장품과 관련된 다양한 활성을 나타내는 것으로 보아 국 화꽃의 기능성 화장품 소재로서의 가능성을 확인하였다.

\section{초 록}

국화(C. morifolium)의 꽃을 $80 \% \mathrm{MeOH}$ 수용액으로 추출한 뒤, 감압농축한 추출물을 EtOAc, $n$-butyl alcohol 및 물분획으 로 나누었다. EtOAc 분획과 $n$-butyl alcohol 분획에 대하여 $\mathrm{SiO}_{2}$ 및 $\mathrm{ODS}$ column chromatography를 반복 실시하여 4종의 flavonoid를 분리, 정제하였다. Nuclear magnetic resonance, infrared spectrometry 및 FAB-MS data를 해석하여, 화합물 14 를 각각 apigenin, acacetin, cosmetin (apigenin-7-O- $\beta$-Dglucopyranoside), acacetin-7-O- $\beta$-D-glucoside으로 구조 동정 하 였다.

Keywords 국화 꽃 · Acacetin · Acacetin-7-O- $\beta$-D-glucoside Apigenin · Cosmetin · Flavonoid · Flower

감사의 글 본 논문은 농촌진흥청 연구사업(세부과제번호: PJ01141501)의 지원에 의해 이루어진 것입니다. 지원에 감사드립니다.

\section{References}

Agar OT, Dikmen M, Ozturk N, Yilmaz MA, Temel H, Turkmenoglu FP (2015) Comparative studies on phenolic composition, antioxidant, wound healing and cytotoxic activities of selected Achillea L. species growing in Turkey. Molecules 20: 17976-18000

Aprotosoaie AC, Mihai CT, Vochita G, Rotinberg P, Trifan A, Luca SV, Petreus T, Gille E, Miron A (2016) Antigenotoxic and antioxidant activities of a polyphenolic extract from European Dracocephalum moldavica L. Ind Crop Prod 79: 248-257

Bouzaiene NN, Chaabane F, Sassi A, Chekir-Ghedira L, Ghedira K (2016) Effect of apigenin-7-glucoside, genkwanin and naringenin on tyrosinase activity and melanin synthesis in B16F10 melanoma cells. Life Sci 144: $80-85$

Coombs MRP, Harrison ME, Hoskin DW (2016) Apigenin inhibits the inducible expression of programmed death ligand 1 by human and mouse mammary carcinoma cells. Cancer Lett 380: 424-433

Kang GH, Chang EJ, Choi SW (1999) Antioxidative activity of phenolic compounds in roasted safflower (Carthamus tinctorius L.) seeds. J Food Sci Nutr 4: 221-225

Karim AA, Azlan A, Ismail A, Hashim P, Gani SSA, Zainudin BH, Abdullah NA (2014) Phenolic composition, antioxidant, anti-wrinkles and tyrosinase inhibitory activities of cocoa pod extract. BMC Complement Altern Med 14: 381

Karlickova J, Riha M, Filipsky T, Macakova K, Hrdina R, Mladenka P (2016) Antiplatelet effects of flavonoids mediated by inhibition of arachidonic acid based pathway. Planta Med 82: 76-83

Komape NPM, Aderogba M, Bagla VP, Masoko P, Eloff JN (2014) Antibacterial and anti-oxidant activities of leaf extracts of Combretum vendae (combretecacea) and the isolation of an anti-bacterial compound. Afr $\mathrm{J}$ Tradit Complement Altern Med 11: 73-77
Lee HJ, Hwang YI, Park E, Choi SU (2011) Antihepatotoxic and antigenotoxic effects of herb tea composed of Chrysanthemum morifolium Ramat. J Food Sci Nutr 40: 78-83

Lee JH, Park KH, Lee MH, Kim HT, Seo WD, Kim JY, Baek IY, Jang DS, Ha TJ (2013) Identification, characterisation, and quantification of phenolic compounds in the antioxidant activity-containing fraction from the seeds of Korean perilla (Perilla frutescens) cultivars. Food Chem 136: 843-852

Lee JS, Kim HJ, Lee YS (2003) A new anti-HIV flavonoid glucuronide from Chrysanthemum morifolium. Planta Med 69: 859-861

Lee YG, Seo KH, Hong EK, Kim DM, Kim YE, Baek NI (2016) Diels-Alder type adducts from the fruits of Morus alba L. J Appl Biol Chem 59: 9194

Malmir M, Gohari AR, Saeidnia S, Silva O (2015) A new bioactive monoterpene-flavonoid from Satureja khuzistanica, Fitoterapia 105: $107-112$

Ministry of Agriculture, Food and Rural Affairs (2014) 2013 Flower Cultivation Status. Ministry of Agriculture, Food and Rural Affairs: 111543000-000108-10

Miyazawa M, Hisama M (2003) Antimutagenic activity of flavonoids from Chrysanthemum morifolium. Biosci Biotechnol Biochem 67: 2091-2099

Mohamed NH (2010) Anticancer activity of Marrubium alysson L. and its phenolic constituents. Recent Progress in Medicinal Plants 27: 185-193

Semwal RB, Semwal DK (2012) Analgesic and anti-inflammatory activities of extracts and fatty acids from Celtis australis L NPJ 2: 323-327

Tavares F, Costa G, Francisco V, Liberal J, Figueirinha A, Lopes MC, Cruz MT, Batista MT (2014) Cymbopogon citratus industrial waste as a potential source of bioactive compounds. J Sci Food Agric 95: 26522659

Thanigaimalai P, Hoang TAL, Lee KC, Bang SC, Sharma VK, Yun CY, Roh E, Hwang BY, Kim Y, Jung SH (2010) Structural requirement(s) of Nphenylthioureas and benzaldehyde thiosemicarbazones as inhibitors of melanogenesis in melanoma B 16 cells. Bioorg Med Chem Lett 20: 2991-2993

Wang G, Zhao Zl, Xue P, Ma F, Zhang D, Wang N, Li M (2015) Chemical constituents from flowers of Scabiosa tschilliensis. Zhongguo Zhong Yao Za Zhi 40: 807-813

Wang Z, Gong Y, Zeng Dl, Chen L, Lin G, Huang C, Sun W, Chen MC, Hu G, Chen R (2016) Inhibitory effect of apigenin on losartan metabolism and cyp2c9 activity in vitro. Pharmacology 98: 183-189

Xiang ZB, Liu XY, Heng LS, Chen YW (2013) Chemical constituents from $n$-butanol extract of Rabdosia japonica var. glaucocalyx. Asian J Chem 136: 843-852

Xie Y, Qu J, Wang Q, Wang Y, Yoshikawa M, Yuan D (2012) Comparative Evaluation of Cultivars of Chrysanthemum morifolium Flowers by HPLC-DAD-ESI/MS Analysis and Antiallergic Assay. J Agr Food Chem 60: 12574-12583

Xie YY, Yuan D, Yang JY, Wang LH, Wu CF (2009) Cytotoxic activity of flavonoids from the flowers of Chrysanthemum morifolium on human colon cancer Colon205 cell. J Asian Nat Prod Res 11: 771-778

Yadav P, Yadava RN (2013) Antioxidant activity of a new flavone glycoside from the seeds of Albizzia odoratissima Benth. Int J of Phyto Pharm 3: $81-85$

Yu ML, Guo YL, Wang JM, Wang CM, Wang AH, Zhang XM, Tu YY, Bai MC (2015) The risk of flavonoids utilization in the anti-tumor therapy. Lat Am J Pharm 34: 627-630

Yuan J, Hao LJ, Wu G, Wang S, Duan J, Xie GY, Qin MJ (2015) Effects of drying methods on the phytochemicals contents and antioxidant properties of chrysanthemum flower heads harvested at two developmental stages. J Funct Foods 19: 786-795

Zheng C, Dong Q, Du Z, Wang P, Ding K (2015) Structural elucidation of a polysaccharide from Chrysanthemum morifolium flowers with antiangiogenic activity. Int J Biol Macromol 79: 674-680 